\title{
Gaining market insights for aquaponically produced vegetables in Kenya
}

\author{
Bart van Gorcum ${ }^{1} \cdot$ Simon Goddek ${ }^{1} \cdot$ Karel J. Keesman $^{1}$
}

Received: 18 December 2017 / Accepted: 3 April 2019 / Published online: 10 May 2019

(C) The Author(s) 2019

\begin{abstract}
Aquaponics is a promising technique which enables continuous pesticide-free food production in arid regions. Substantial research has been done with respect to aquaponics technologies and production. However, the demand side of the market has not been investigated in much detail yet. This exploratory study analysed the Nairobian market for aquaponically produced foods. Interviews provided data to get some first insights into the market prices and customers' perception of aquaponically produced food products. Results showed that the majority of the interviewees claim to be willing to pay more for aquaponically produced food products.
\end{abstract}

Keywords Aquaponics · Agriculture $\cdot$ Market research $\cdot$ Kenya $\cdot$ Integrated agriculture $\cdot$ Organic agriculture

\section{Introduction}

In the wake of climate change, innovative agricultural approaches to food security, particularly in countries facing water scarcity and chronic drought, are required. In this respect, the concept of aquaponics has been determined as a farming key technology that can aid in addressing sustainable development goals, particularly for arid regions (Conijn et al. 2018). Aquaponics can be seen as an integrated multi-trophic food production system that combines elements of recirculating aquaculture (RAS) and hydroponics. In aquaponic systems, water from the fish tanks, which is enriched in nutrients, is used for plant growth. Increased sustainability of such aquaponics systems are achieved by re-using RAS-derived nutrient and waste (Goddek et al. 2015).

One of the most significant current discussions in the field of aquaponics is the economic viability of such systems (Bosma et al. 2017; Stadler et al. 2017; Vermeulen and Kamstra

Simon Goddek

simon.goddek@wur.nl

Karel J. Keesman

karel.keesman@wur.nl

1 Biobased Chemistry \& Technology, Wageningen University, P.O. Box 17, 6700 AA Wageningen, The Netherlands 
2013). However, given current improvements in performance, based on the development of multi-loop aquaponics systems, it is most likely that such systems will be able to compete, if not excel state-of-the-art hydroponics systems (Goddek et al. 2016; Goddek and Keesman 2018). While aquaponics is a promising technique, market research in regards to products from aquaponics farms received scant attention in the research literature. The research to date has rather tended to focus on the supply side than on the demand side of the Western market (Love et al. 2014, 2015). In addition to Love et al. (2014, 2015), Miličić et al. (2017) also investigated the demand side of aquaponics, by looking into the consumers' perception and knowledge of aquaponics by consumers, concluding that no more than $17 \%$ of the respondents were willing to pay more for aquaponically produced food products. However, most research on the economic viability of aquaponics has been carried out in developed markets.

To address this research gap, the primary objective of this exploratory study was to gain insight into the demand side of the East-African market for aquaponically produced food products in Nairobi, Kenya. Furthermore, we aimed to determine the local customers' perception of aquaponically produced food products.

\section{Methodology}

This exploratory research employed an interview methodology to investigate the supply prices and customers' perception. A semi-structured interview was used, where the interview could be completed within $10 \mathrm{~min}$. The interview consisted of two parts: (1) perception of the aquaponics concept and (2) the current market prices of vegetables. With respect to the perception questions, the concept of aquaponics, on a seven-point Likert scale (Likert 1932) from strongly disagree to strongly agree, was used. The stated willingness-to-pay was measured by a direct question. Both the willingness-to-pay and the attributes about aquaponics were rated after aquaponics was defined. The definition of aquaponics from the research of Miličić et al. (2017) was used: "a combination of aquaculture (fish farming) and hydroponics (growing plants using water rather than soil). In aquaponics, the waste produced by farmed fish supplies the nutrients for plants grown hydroponically, which in turn purifies water for the fish. This secures a closed-loop sustainable food production system. Very few pesticides and herbicides are non-toxic for fish so this ensures that aquaponics production uses organic pest and weed control." Thereby, the following sentence was added: "So, aquaponic products are sustainable, local and organic products."

The sample was obtained by convenience and snowball sampling, the only criteria was that the hotel/restaurant/retailer is located in Nairobi. The interviews and observations took place in October and November 2017. The sample size for the research about perception and supply consisted of 14 restaurants/hotels/retailers. These data were obtained by visiting restaurants, hotels and retailers, and interviewing the personnel. The supply prices of the organic vegetables were obtained by contacting organic farmers who supply to restaurants, hotels and retailers. The supply prices of the conventional vegetables were obtained by interviewing personnel of retailers, hotels and restaurants.

\section{Statistical analysis}

Simple statistical analysis was used to process the data. The data showed outliers. Therefore, in this exploratory study it was decided that the best method to analyse the data was comparing 
medians, to minimise the impact of the outliers. Statistical significance was analysed using the Kolmogorov-Smirnov test. A $p$ value $<0.05$ was considered significant. Data management was performed in a Microsoft Excel 2017 environment. Statistical analyses were carried out using SPSS version 21.

\section{Results}

Table 1 gives an overview of the prices that the restaurants, hotels and retailers pay to their suppliers. A distinction is made between products, which are sold as organic and products that are sold as conventional produce. The price differences between conventional and organic products are highlighted in the last column. The exchange rate of 8 December 2017 (i.e. 1 Euro = $121 \mathrm{KSh}$ ) is used to calculate the prices in Euro. The data in the table show that organic products are not necessarily sold for higher prices. Even though we did not observe any significant differences in selling prices between organic and conventional vegetables, the low $p$ value of 0.07 for soft lettuce and eggplant, respectively, indicates that the trend goes in the direction of higher supply prices for organic produce.

In addition, interviewees were asked to explain what aquaponics is. None of them were familiar with the concept. Four characteristics of aquaponically produced food products were shown and rated on a seven point Likert scale (from strongly disagree to strongly agree). The results are shown in Table 2.

Table 1 Conventional products and their organic variant with corresponding supply prices

\begin{tabular}{|c|c|c|c|c|c|c|c|c|c|c|}
\hline \multirow[b]{3}{*}{ Product } & \multirow[b]{3}{*}{ Unit } & \multicolumn{3}{|l|}{ Conventional } & \multicolumn{3}{|l|}{ Organic } & \multicolumn{3}{|c|}{ Difference } \\
\hline & & \multirow[t]{2}{*}{ Observations $(n)$} & \multicolumn{2}{|c|}{ Median } & \multirow[t]{2}{*}{ Observations $(n)$} & \multicolumn{2}{|c|}{ Median } & \multicolumn{3}{|c|}{ Organic-conventional } \\
\hline & & & KSh & Euro & & KSh & Euro & KSh & Euro & $p$ value \\
\hline Basil & bunch & 6 & 30 & 0.25 & 3 & 30 & 0.25 & 0 & 0.00 & 1.00 \\
\hline $\begin{array}{l}\text { Bell pepper, } \\
\text { green }\end{array}$ & $\mathrm{kg}$ & 5 & 130 & 1.07 & 3 & 120 & 0.99 & -10 & -0.08 & 0.79 \\
\hline $\begin{array}{l}\text { Bell pepper, } \\
\text { red and } \\
\text { yellow }\end{array}$ & $\mathrm{kg}$ & 5 & 250 & 2.07 & 2 & 200 & 1.65 & -50 & -0.41 & 1.00 \\
\hline Broccoli & $\mathrm{kg}$ & 5 & 190 & 1.57 & 5 & 200 & 1.65 & 10 & 0.08 & 1.00 \\
\hline Celery & $\mathrm{kg}$ & 7 & 150 & 1.24 & 4 & 125 & 1.03 & -25 & -0.21 & 0.41 \\
\hline Chives & bunch & 5 & 20 & 0.17 & 4 & 30 & 0.25 & 10 & 0.08 & 0.19 \\
\hline Coriander & bunch & 7 & 40 & 0.33 & 6 & 30 & 0.25 & -10 & -0.08 & 0.45 \\
\hline $\begin{array}{c}\text { Cucumber, } \\
\text { Kenyan }\end{array}$ & $\mathrm{kg}$ & 6 & 120 & 0.99 & 2 & 95 & 0.79 & -24.5 & -0.20 & 0.67 \\
\hline Dill & bunch & 7 & 35 & 0.29 & 3 & 30 & 0.25 & -5 & -0.04 & 0.67 \\
\hline Eggplant & $\mathrm{kg}$ & 7 & 80 & 0.66 & 2 & 110 & 0.91 & 30 & 0.25 & 0.07 \\
\hline Lettuce, soft & piece & 5 & 38 & 0.31 & 3 & 50 & 0.41 & 12 & 0.10 & 0.07 \\
\hline $\begin{array}{l}\text { Lettuce, } \\
\text { Iceberg }\end{array}$ & piece & 5 & 50 & 0.41 & 3 & 50 & 0.41 & 0 & 0.00 & 0.79 \\
\hline Mint & bunch & 8 & 27 & 0.22 & 4 & 30 & 0.25 & 3.5 & 0.03 & 1.00 \\
\hline Parsley & bunch & 8 & 33 & 0.27 & 3 & 30 & 0.25 & -2.5 & -0.02 & 0.92 \\
\hline Spinach & bunch & 8 & 31 & 0.26 & 7 & 40 & 0.33 & 9 & 0.07 & 0.40 \\
\hline Tomatoes & $\mathrm{kg}$ & 7 & 110 & 0.91 & 5 & 120 & 0.99 & 10 & 0.08 & 0.27 \\
\hline
\end{tabular}


Table 2 Customers' $(n=14)$ ratings on four fixed characteristics, rated on a seven-point Likert scale

Factor

Mean $\pm \mathrm{SD}$

Naturalness

$6.3 \pm 1.1$

Healthiness

$6.5 \pm 1.0$

Freshness

$6.5 \pm 1.0$

Free of contamination

$6.4 \pm 1.0$

In the final part of the survey, the interviewees were asked to give their willingness to pay for aquaponically-produced food products in comparison to conventional products. None of the interviewees claimed to be willing to pay less for aquaponically produced food products. Figure 1 presents an overview of the willingness to pay. Regarding the willingness-to-pay objective, after the concept of aquaponics was explained, $70 \%$ of the respondents claimed to be willing to pay more for aquaponically produced food products in comparison to conventionally produced food products. Of the interviewees willing to pay more, most were willing to pay between $10 \%$ and $25 \%$ more.

The quality and seasonality of the products was a recurrent theme during the interviews. For example, an often-mentioned product with quality issues was asparagus. One restaurant owner stated that the asparagus offered on the Kenyan market is excessively thin and therefore asparagus is generally imported. Local cherry tomatoes were also mentioned several times as being of inferior quality. In terms of seasonality, the quality of most products is considered low, which is especially the case for potatoes during the rainy season. Three months after the rainy season, the climate is the driest, which typically leads to much higher domestic supply prices.

Not all the products, which are sold as organic, have an organic certification. In the interviews, negative comments about organic certifications were made. In particular, two interviewed "organic" farms indicated that they stopped using this certification, due to a lack of trust in the certification procedure. Another branch manager of a vegetable store mentioned that it is currently hard to distinguish between conventional and organic products, which is the main reason why they do not sell organic products at all. The manager proposed individual packaging of organic products to ensure that conventional products are not mixed with organic products.

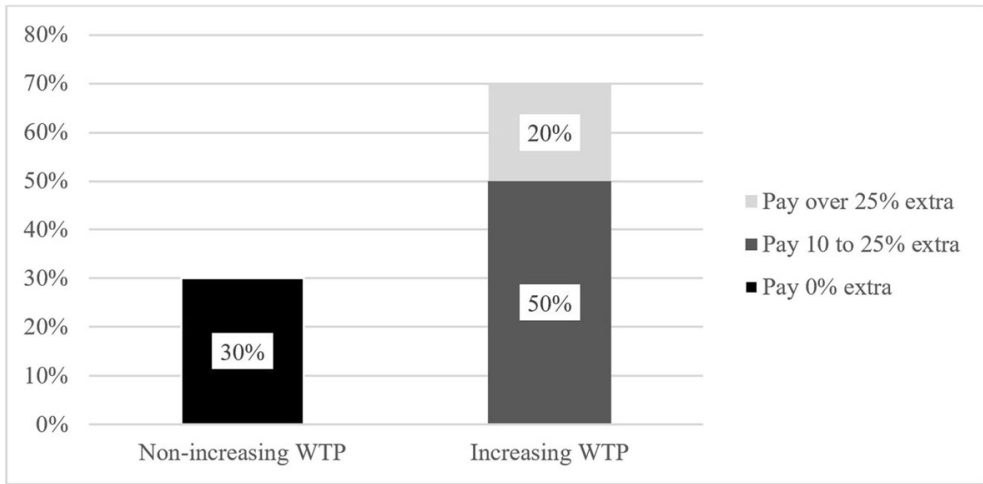

Fig. 1 Willingness-to-pay (WTP) for aquaponically produced food products 


\section{Discussion}

The main objective of this research was to get insight into market prices for aquaponically produced food products. It turned out that in Nairobi, Kenya, there are generally no significant differences in market prices between organic branded and nonorganic branded vegetables. An interesting finding of this exploratory study was that there is a lack of high-quality vegetables on the market. Currently, vegetables show spots and some are even spoiled. Interviews with two major retailers stressed the need for high-quality vegetables and that the current diversity of vegetables is limited. Another interviewee stated that the quality of some vegetables on the market is very low, so that e.g. asparagus and artichokes have to be imported. This is most likely because poor production methods are used, pesticides are overused, as well as bad weather conditions (Lenné and Ward 2010). In addition, poor logistics and non-cooled storage may lead to long transport times and deterioration of the products during transport and storage(van der Lans et al. 2012). With respect to the bad quality of the supplied vegetables, it has to be noted that most of the greenhouse horticulture industry in Kenya focuses on growing flowers for the export market (Rikken 2011; Veselinovic 2015).

Our observations with respect to willingness-to-pay are not in accordance with to the study of Zugravu et al. (2016), who showed that Romanian customers have a negative image regarding the health of fish produced in farms. The current study shows that the interviewees in Nairobi did not have any negative remark about fish produced in aquaponic farms. However, almost all interviewees mentioned that the best fish come from Lake Victoria and not from fish farms. We assume that this is most likely due to off-flavour resulting from suboptimal production procedures, as a result of inappropriate pre-harvest fish treatment (DeLong et al. 2009; Goddek 2017; Schrader et al. 2013)

Aquaponics, on the other hand, enables a constant, continuous production throughout the whole year, as the crops and fish grow in a more controlled environment. Therefore, aquaponics provides a potential option to grow perennial high-quality fruits and vegetables as well as fish products. Also, the customers' perception with respect to organic food and using pesticides appeared to be contradictory in Kenya. Even though some interviewees stressed the importance of having access to organic products, they also considered pesticides necessary to produce organic vegetables. This view on food production might be due to a lack of knowledge of the minority of the interviewees, especially since others were especially aware of the excessive use of pesticides and fungicides.

Perceived costs and benefits are major determinants of consumers' acceptance of innovations from food technology and the technology itself (Ronteltap et al. 2007). Therefore, it is recommended to do further research in the consumers' and customers' perception by investigating the perceived costs and benefits of aquaponically produced foods. Also, it is recommended to use indirect surveys to measure the willingness-to-pay for aquaponically produced food products since this may give more valid estimates (Breidert et al. 2006). The market prices in the Results section of this exploratory study are based on 14 interviews; the data of the overview showed substantial variation. Future research with a larger sample can give a more valid estimation for the prices of the whole Nairobian market. The current study was restricted to customers' rather than consumers' (end-customer) perceptions, further work is needed to get understanding of the consumers' perceptions and acceptance of aquaponically produced foods in Kenya. During the field visits, it became clear that the supply chain is very 
pluriform and it was observed that prices for a certain product can have a substantial difference amongst different suppliers. Further studies need to be done to get an understanding of the supply chain and the pricing mechanisms at each step of the supply chain.

\section{Conclusions}

- Restaurants, hotels and retailers do not pay clearly higher prices for products that claimed to be produced organically in comparison to conventionally produced vegetables.

- Interviewees generally agree that production in aquaponics is natural, fresh, healthy and free of pesticides.

- The market potential for aquaponics products exists according to the increased consumer's willingness to pay for it.

- Aquaponics could provide a solution to bypass seasonal production issues due to climatic conditions in Kenya.

Acknowledgements A big thanks to the project's partners TGS, Developonics absl., and Tinder Ltd for their support.

Author contributions Bart van Gorcum is the main author of this manuscript. He was assisted by the other coauthors in form and content.

Funding information This work is part of a project that has received funding from the VIAWater programme, project number L17040/VW468.

\section{Compliance with ethical standards}

Conflict of interest The authors declare that they have no conflict of interest.

Open Access This article is distributed under the terms of the Creative Commons Attribution 4.0 International License (http://creativecommons.org/licenses/by/4.0/), which permits unrestricted use, distribution, and reproduction in any medium, provided you give appropriate credit to the original author(s) and the source, provide a link to the Creative Commons license, and indicate if changes were made.

\section{References}

Bosma RH, Lacambra L, Landstra Y, Perini C, Poulie J, Schwaner MJ, Yin Y (2017) The financial feasibility of producing fish and vegetables through aquaponics. Aquac Eng 78:146-154. https://doi.org/10.1016/J. AQUAENG.2017.07.002

Breidert C, Hahsler M, Reutterer T (2006) A review of methods for measuring willingness-to-pay. Innov Mark 2(4):8-32

Conijn JG, Bindraban PS, Schröder JJ, Jongschaap REE (2018) Can our global food system meet food demand within planetary boundaries? Agric Ecosyst Environ 251:244-256. https://doi.org/10.1016/J. AGEE.2017.06.001

DeLong DP, Losordo TM, Rakocy JE, (2009) Tank Culture of Tilapia. SRAC Publication No. 282.

Goddek S, (2017) Opportunities and Challenges of Multi-Loop Aquaponic Systems. Wageningen University, Wageningen. https://doi.org/10.18174/412236 
Goddek S, Keesman KJ (2018) The necessity of desalination technology for designing and sizing multi-loop aquaponics systems. Desalination 428:76-85. https://doi.org/10.1016/j.desal.2017.11.024

Goddek S, Delaide B, Mankasingh U, Ragnarsdottir K, Jijakli H, Thorarinsdottir R (2015) Challenges of sustainable and commercial aquaponics. Sustainability 7:4199-4224. https://doi.org/10.3390/su7044199

Goddek S, Espinal CA, Delaide B, Jijakli MH, Schmautz Z, Wuertz S, Keesman KJ (2016) Navigating towards decoupled aquaponic systems: a system dynamics design approach. Water (Switzerland) 8:303. https://doi. org/10.3390/W8070303

Lenné JM, Ward AF (2010) Improving the Efficiency of domestic vegetable marketing systems in East Africa. Outlook Agric 39:31-40. https://doi.org/10.5367/000000010791169952

Likert R, (1932) A technique for the measurement of attitudes. Archives of Psychology 22 140, 55-55.

Love DC, Fry JP, Genello L, Hill ES, Frederick JA, Li X, Semmens K (2014) An international survey of aquaponics practitioners. PLoS One 9:1-10

Love DC, Fry JP, Li X, Hill ES, Genello L, Semmens K, Thompson RE (2015) Commercial aquaponics production and profitability: findings from an international survey. Aquaculture 435:67-74

Miličić V, Thorarinsdottir R, Santos M, Hančič M (2017) Commercial aquaponics approaching the European market: to consumers' perceptions of aquaponics products in Europe. Water 9:80. https://doi.org/10.3390 /w9020080

Rikken M, (2011) The global competitiveness of the Kenyan flower industry (Technical paper).

Ronteltap A, Van Trijp JCM, Renes RJ, Frewer LJ (2007) Consumer acceptance of technology-based food innovations: lessons for the future of nutrigenomics. Appetite 49(1):1-17

Schrader KK, Davidson JW, Summerfelt ST (2013) Evaluation of the impact of nitrate-nitrogen levels in recirculating aquaculture systems on concentrations of the off-flavor compounds geosmin and 2methylisoborneol in water and rainbow trout (Oncorhynchus mykiss). Aquac Eng 57:126-130. https://doi. org/10.1016/j.aquaeng.2013.07.002

Stadler MM, Baganz D, Vermeulen T, Keesman KJ, (2017) Circular economy and economic viability of aquaponic systems: Comparing urban, rural and peri-urban scenarios under Dutch conditions. International Society for Horticultural Science, pp. 101-114. https://doi.org/10.17660 /ActaHortic.2017.1176.14

van der Lans C, Snoek H, de Boer F, Elings A (2012) Vegetable chains in Kenya: production and consumption of vegetables in the Nairobi metropolis. Wageningen UR Centre for Development Innovation Rapport GTB1130, Wageningen

Vermeulen T, Kamstra A, (2013) The need for systems design for robust aquaponic systems in the urban environment.

Veselinovic M, (2015) Got roses this Valentine's Day? They probably came from Kenya. CNN.

Zugravu AG, Rahoveanu MMT, Rahoveanu AT, Khalel MS, Ibrahim MAR, (2016) The Perception of Aquaponics Products in Romania. Risk in Contemporary Economy 525-530.

Publisher's note Springer Nature remains neutral with regard to jurisdictional claims in published maps and institutional affiliations. 